\title{
Aspectos físicos, bióticos e socioambientais do estado de Goiás e do Distrito Federal
}

\author{
Wilian Vaz-Silva \\ Natan Medeiros Maciel \\ Fausto Nomura \\ Alessandro Ribeiro de Morais \\ Vinícius Guerra Batista \\ Danusy Lopes Santos \\ Sheila Pereira Andrade \\ Arthur Ângelo Bispo de Oliveira \\ Reuber Albuquerque Brandão \\ Rogério Pereira Bastos
}

\section{SciELO Books / SciELO Livros / SciELO Libros}

VAZ-SILVA, W., MACIEL, N.M., NOMURA, F., MORAIS, A.R., BATISTA, V.G., SANTOS, D.L., ANDRADE, S.P., OLIVEIRA, A.Â.B., BRANDÃO, R.a., BASTOS, R.P. Aspectos físicos, bióticos e socioambientais do estado de Goiás e do Distrito Federal. In: Guia de identificação das espécies de anfíbios (Anura e Gymnophiona) do estado de Goiás e do Distrito Federal, Brasil Central [online]. Curitiba: Sociedade Brasileira de Zoologia, 2020, pp. 12-13. Zoologia: guias e manuais de identificação series. ISBN: 97865-87590-01-1. https://doi.org/10.7476/9786587590011.0002. \section{International license.}

All the contents of this work, except where otherwise noted, is licensed under a Creative Commons Attribution 4.0

Todo o conteúdo deste trabalho, exceto quando houver ressalva, é publicado sob a licença Creative Commons Atribição 4.0. 
1.4. Os oscilogramas e espectogramas foram obtidos com auxílio do programa R 3.0.3 (Seewave package - Sueur et al. 2008). A temperatura e a umidade relativa do ar foram registradas com termo-higrômetro Instrutherm ${ }^{\circledR}$. O comprimento rostro-cloacal (CRC) e o peso dos indivíduos gravados foram registrados com paquímetro (precisão de $0,1 \mathrm{~mm}$ ) e balança digital (precisão de $0,01 \mathrm{~g})$, respectivamente.

Os animais adultos coletados foram anestesiados com lidocaína, fixados em solução de formalina a $10 \%$ e, posteriormente, conservados em álcool a $70 \%$. Girinos e adultos foram fixados em solução de formol 10\%, sendo conservados também nesta solução. Exemplares testemunhos foram depositados, principalmente nas coleções zoológicas da Universidade Federal de Goiás (ZUFG) e da Pontifícia Universidade Católica de Goiás (CEPB-PUCGO). Outras coleções zoológicas, como a do Museu Nacional, Rio de Janeiro (MNRJ); do Departamento de Zoologia e Botânica, Universidade Estadual Paulista, campus de São José do Rio Preto (DZSJRP); da coleção Célio Fernando Baptista Haddad (CFBH), na Universidade Estadual Paulista, campus de Rio Claro, da Universidade de Brasília (CHUNB) e do Museu de Zoologia, da Universidade de São Paulo (MZUSP) também preservam exemplares de anfíbios do Distrito Federal e do estado de Goiás e são considerados importantes repositórios do conhecimento dessa fauna.

\section{Aspectos físicos, bióticos e socioambientais do estado de Goiás e do Distrito Federal}

O estado de Goiás, com 340.165,9 km², e o Distrito Federal, com 5.814 km² estão localizados no core do bioma Cerrado. entre os paralelos $13^{\circ} 00^{\prime}$ e $19^{\circ} 00^{\prime} \mathrm{S}$ e os meridianos $46^{\circ} 00$ e $53^{\circ} 00 \mathrm{~W}$ (Nascimento 1991). O clima, de modo geral, é do tipo "Aw" (Tropical Savânico), com os 12 meses apresentando temperatura média mensal superior a $18^{\circ} \mathrm{C}($ (" $\mathrm{A}$ "), período seco de inverno (" $\mathrm{W}$ "), além de amplitude térmica anual inferior a $5{ }^{\circ} \mathrm{C}$ (isotermal) (Alvares et al. 2013). Desta forma, corresponde a duas estações bem definidas: a seca, entre os meses de abril a setembro, apresentando variação de temperatura entre $\sim 20,8$ e $24,2^{\circ} \mathrm{C}$; e a chuvosa, entre os meses de outubro a março, com variação de temperatura de $\sim 24,1$ a $25,3^{\circ} \mathrm{C}$ (Dias Cardoso et al. 2012).

Considerando os compartimentos de relevo, reconhecemos a presença de cinco grandes unidades geomorfológicas e onze subunidades: 1) Planalto Central Goiano (Planalto do Distrito Federal, Planalto do Alto Tocantins-Paranaíba, Planalto Rebaixado de Goiânia e Depressões Intermontanas); 2) Planalto Setentrional da Bacia do Paraná (Planalto de Caiapônia e Planalto de Rio Verde); 3) Planalto do Divisor São Francisco/Tocantins (Patamares do Chapadão); 4) Depressão do Tocantins (Vão do Paranã e Depressão dos rios Maranhão/Santa Tereza); e 5) Depressão do Araguaia (Depressão do rio Araguaia e Planície do Bananal) (Nascimento 1991). Este padrão geomorfológico resulta numa variação altitudinal expressiva variando entre 200 m (na Depressão do Araguaia) e 1676 m na Serra do Pouso Alto, Chapada dos Veadeiros), ponto mais alto do estado, no município de Alto Paraíso de Goiás. Em relação à rede de drenagens, existem contribuintes para a formação de três grandes bacias hidrográficas, sendo elas a bacia Tocantins-Araguaia, a do Paraná e a do São Francisco.

O uso do solo, com exceção às áreas de aglomerados urbanos, é atrelado às atividades econômicas 
voltadas para o agronegócio e mineração. A pecuária praticada de forma generalizada no estado ocupa vastas áreas, principalmente nas regiões norte, nordeste e noroeste do estado, enquanto a agricultura se concentra na porção que drena para a bacia do rio Paraná, principalmente nas regiões sudeste, sul e sudoeste de Goiás.

A vegetação de Goiás e do Distrito Federal são predominantemente de feições savânicas, com manchas de florestas estacionais, com pequena invaginação da Mata Atlântica em alguns segmentos do rio Paranaíba (IBGE 2004). Os principais remanescentes de vegetação estão na região norte-nordeste do estado, com índices de cobertura variando entre $65 \%$ e $87 \%$, enquanto que, nas demais regiões, principalmente sudoeste e sul, a proporção de remanescentes naturais está abaixo de 20\% (Carvalho et al. 2008).

Os diferentes tipos de solo e relevo propiciam a incidência de diferentes tipos fitofisionômicos e de uso do solo. A paisagem do bioma Cerrado é caracterizada pela presença de formações florestais, savânicas e campestres. As formações florestais são classificadas como justafluviais [floresta de galeria (mata de galeria) e floresta estacional aluvial (mata ciliar)] e de interflúvio [floresta estacional decidual e semidecidual (matas secas deciduais e semideciduais) e savana florestada (cerradão)]. Por outro lado, as formações savânicas são classificadas como savana arborizada (cerrado típico), savana parque (cerrado ralo) e savana graníneo-lenhosa (campo sujo e limpo) (ver Ribeiro \& Walter 1998, IBGE 2004).

A diversidade faunística tende a estar relacionada com diversas características do ambiente, tais como disponibilidade de recursos e interações ecológicas, resultando em assembleias mais generalistas ou especialistas no uso do espaço e dos recursos. No contexto zoogeográfico, a anfibiofauna do bioma Cerrado é caracterizada por espécies de direrentes requisitos ambientais, como aquelas de ampla distribuição bem como aquelas de distribuição mais restrita, com elementos típicos de outros biomas nas porções de contato, como a Amazônia e a Caatinga (Brandão \& Araujo 2002, Vaz-Silva \& Andrade 2009, Valdujo et al. 2012). 